\title{
Infusing the Elements of Sustainability into Entrepreneurial Orientation Construct: An Approach to Intensify the Development of Business Enterprises
}

\author{
Nandini Sharma*, Jyoti Gogia \\ Department of Economics, Faculty of Social Sciences, Dayalbagh Educational Institute (Deemed University), \\ Dayalbagh, Agra, 282005, Uttar Pradesh, India \\ *Corresponding Author: ecstatic.nandini@gmail.com
}

Copyright $@ 2014$ Horizon Research Publishing All rights reserved.

\begin{abstract}
In the contemporary times, it is not just development, but Sustainable Development that tops the vision chart of almost every business enterprise. In this age of advancement, entrepreneurs are succeeding in being entrepreneurially oriented as they get trained in first-rate institutions, but they still have less acquaintance with the concept of Sustainability, which leads to its low adaptability. This is the reason that it is still considered as a vision than a goal. The elements of Sustainability are tremendously required to be integrated with the dimensions of the Entrepreneurial Orientation Construct. The study scrutinizes the association between Sustainability elements and Entrepreneurial dimensions. A framework has been devised to efficiently instill the elements of Sustainability into the entrepreneurial base so that the progress of the business enterprises can live long.
\end{abstract}

Keywords Entrepreneurial Dimensions, Sustainability Elements, Entrepreneurial Orientation Construct, Sustainable Development

JEL Codes L26, M14, M21, Q01

\section{Introduction}

For the economic development of a country, while emphasizing on the term 'economic', it is outright that there are four factors of production that build up an economy. These include - Land, Labor, Capital and Enterprise. In all of them, the most important one is an Enterprise, which is sufficient enough to exhaust the rest of the three. Thus, the entrepreneurial base of a country is the most prominent set-up that also fabricates its economy. An entrepreneur is the person that establishes an enterprise. The operational working of an organization depends upon his skills. The new introduced term - Entrepreneurial Orientation (EO) provides a measurement base of these skills. But, in the present times, it is not enough for an entrepreneur to be merely entrepreneurially oriented in order to bring profits to his venture. In fact, he needs to add up certain facets that can escalate and retain the progress of his enterprise. The budding concept of - Sustainable Development (SD) is thus in vogue. Researchers, of almost all disciplines, are occupied in locating ways to best utilize this concept. It is a complete notion that deals with present and takes care of the future generations, thereby covering the three dominant spheres Society, Economy, and Environment. An enterprise is successful, if it is good at sustaining its development and growth. Incorporating sustainable processes into a business model can indeed make the business more efficient and reduce costs [14]. Hence, it is needed that the two different concepts - Entrepreneurial Orientation and Sustainable Development work simultaneously and in a synchronized manner.

\subsection{Objective of the Study}

The study was initiated with the objective of analyzing the link between the Elements of Sustainability and the Dimensions of Entrepreneurial Orientation Construct. It further led to investigate the ways of instilling Sustainability elements into the Entrepreneurial Orientation Construct.

\subsection{Entrepreneurial Orientation Construct}

"An entrepreneurial firm is one that engages in product market innovation, undertakes somewhat risky ventures, and is first to come up with proactive innovations, beating competitors to the punch" - Miller [4]. All of these aspects can be summed up to provide us with a single term Entrepreneurial Orientation, which can be defined as a multi-dimensional construct, applied at the organizational level. It characterizes the firm's entrepreneurial behavior. It contributes to the firm's performance and is labeled as 'a compound measure incorporating dimensions of growth as well as financial performance' - Wiklund [9]. 
Basing on the study of Khandwalla [15], who considered that a firm must be essentially risk-bearing and proactive in order to be entrepreneurial, Miller and Friesen [3] went on to develop an instrument for empirically assessing the dimensions within a firm, added by a strong emphasis on new product innovation. Covin and Slevin [8] developed an Entrepreneurial Orientation scale to measure the three dimensions along with their three sub-dimensions. This scale consisted of nine items - three items measuring innovativeness, three items measuring proactiveness, and three items measuring risk taking. Two dimensions Competitive Aggressiveness and Autonomy, were further added by Lumpkin and Dess [7] to the existing Entrepreneurial Orientation Scale.

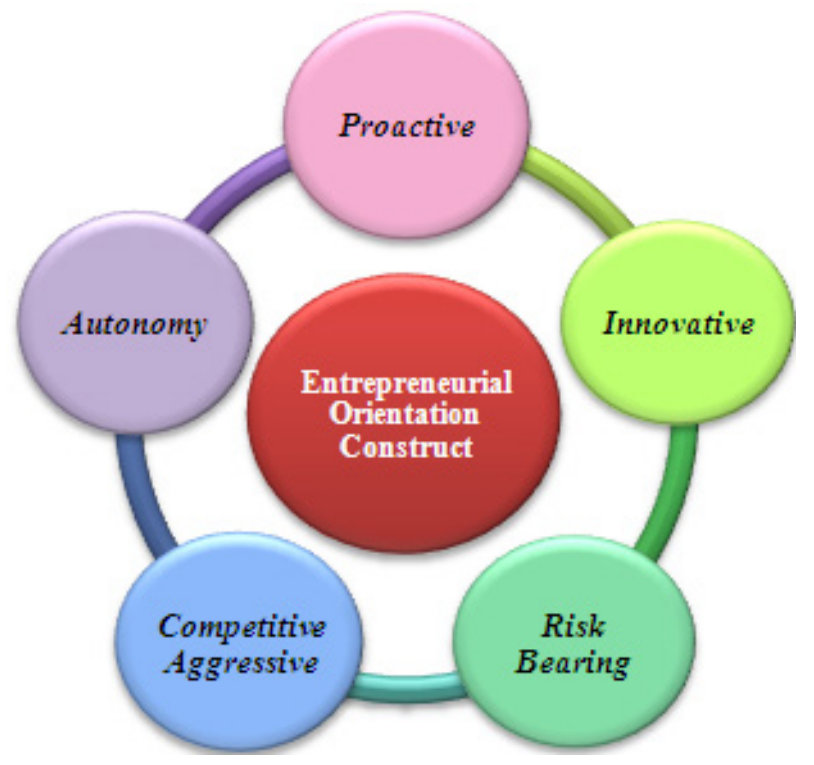

Figure 1. The Entrepreneurial Orientation Construct

The factors for the construct (figure 1.) taken in this study are as per Lumpkin and Dess [7]. Hereby, these factors are briefly described. Proactiveness is termed as taking initiative by anticipating and pursuing new opportunities and by participating in emerging markets. It suggests a forward-looking perspective that is accompanied by innovative or a new-venturing activity. Autonomy refers to the independent action of an individual or a team in bringing forth an idea or a vision and carrying it through to its completion. In general, it means the ability and determination to be self-directed in the pursuit of opportunities. Innovativeness reflects a firm's inclination towards emerging with new concepts and ideas, adding up creativity in the working processes, launching unique products and services, and also experimenting with new techniques and technologies. Competitive Aggressiveness refers to a firm's tendency to directly and intensely challenge its competitors to enter or improve their position in the marketplace. It indicates to outperform the industry rivals. Risk Bearing is the propensity with which the entrepreneurs are willing to commit huge investments and it is their ability to withstand the uncertainties of any kind.

\subsection{Elements of Sustainability}

As defined by the Brundtland Commission (WCED) [18] in its report in 1987, "Sustainable Development is that which meets the needs of the present without compromising the ability of future generations to meet their own needs." It is a process in which Sustainability or Sustainable Future is the endpoint [13]. The state of Sustainability is achieved when its three parameters - Social, Economic and Environmental Sustainability are efficiently met.

A nation is developed in true sense, when its people are in a healthier state of living. This can be acquired when the resources are used in a way that every social being of present and next generation gets all the basic amenities, including education, health facilities, employment, etc, on a relatively equal basis. This is known as Social Sustainability. The mentioned standards of living can be only provided to the community when there is efficient production and distribution of goods and services in the country, which means a sound economy. If the economic functioning of this day promises the upcoming generation with the provision of same or better quality of wealth and resources, then it is termed as Economic Sustainability. Most nature items are used as raw materials in the process of manufacturing. The efficient employment and also conservation of natural products and energies will help in attaining Environmental Sustainability. A healthy environment is deep-seated for the survival of the society which is engaged in the economic operations of a country.

In the recent times, Sustainable Development is preferred in every sphere. For recognizing Sustainability in the business world, certain elements of it (figure 2.) need to be adopted. These elements are - Leadership, as a prominent economic aspect, it leads to directional working; Ethics and Values are the features that support the community, for which an enterprise is established; and Environmental Consciousness as a representative, enables the achievement of Environmental Sustainability. The development of a Business Enterprise can be sustained, only if the mentioned three elements of Sustainability are altogether chased and adjoined with the Entrepreneurial dimensions in the righteous proportion by an entrepreneur.

\subsection{Sustainable Entrepreneurial Orientation Construct}

Infusing the Sustainability elements with the Entrepreneurial Orientation dimensions (figure 3.) has led to the evolution of a new construct consisting of fifteen parameters and is named as the Sustainable Entrepreneurial Orientation Construct. The equivalent satisfaction of adopting each parameter shall result in the establishment of a Sustainable Entrepreneurial Base. Sustainable Entrepreneurs supposedly display a different mentality as evidenced through donations to environmental causes, employee-friendly working conditions, an interest in wider social issues than bottom-line profits and a concern for the longer-term implications of their business activities $[5,6]$. 


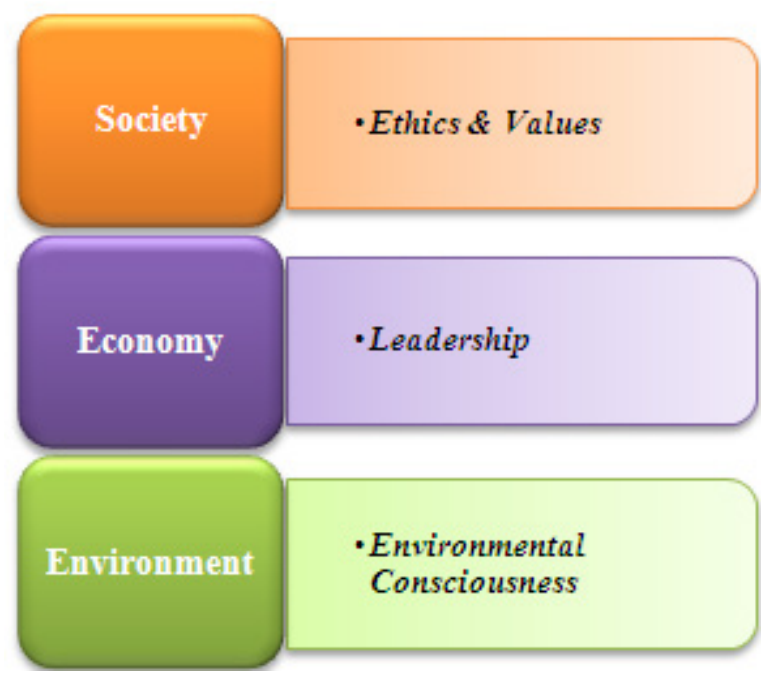

Figure 2. Construct for Sustainable Development of Business Enterprises

\subsubsection{Proactive Leadership}

It is the skill of an entrepreneur to lead his team, where all the way, he is highly alert, takes decisions in time, and gets updated with all the information. It is the most acquired quality of an entrepreneur.

\subsubsection{Ethical Proactiveness}

An activated entrepreneur needs to stay ethical throughout, so as to prolong his standing in the market. The ethical working must be in favor of the society, which includes the consumers and the employees.

\subsubsection{Eco-Conscious Proactiveness}

Working beforehand, with an objective to preserve the environment, means Eco-conscious Proactiveness. One way is to set specific targets for future environmental performance for outcomes, inputs and processes. Green concerns do not depend on a tremendous investment but more on a proactive approach, managerial ability and commitment tied to smart investment [12].

\subsubsection{Innovative Leadership}

It is about how creatively can an entrepreneur guide his team and explore the hidden ideas to take up his enterprise with an exclusive performance. Deputation of assignments that are artistically processed and exhibiting creativity filled advertisements are some different ways to lead the market.

\subsubsection{Ethical Innovation}

Innovation is substantial only when it is original, i.e., ethically gained from within. Copying others' ideas might lead to success but that definitely cannot last for long and this may also show its harmful consequences in the future.

\subsubsection{Eco-Conscious Innovation}

If innovation is done with respect to environmental care, it will surely add up the gains for long run. Green is getting into fashion, especially with the developed class. Innovations like, inventing new green technologies to work and using eco-friendly raw products to fabricate the finished ones, needs to be chased always.

\subsubsection{Risk-Bearing Leadership}

An entrepreneur is always stuck with risks. He is not qualified as an entrepreneur if he doesn't bear any risk. Thus, risk is the part and parcel of an entrepreneur's life. But, risk-bearing leadership is all about how efficiently he manages them along with his team.

\subsubsection{Ethical Risk-Bearing}

Risks are borne by all entrepreneurs, but those approaching towards Sustainable Development, bear it ethically. Some spread their risks on to their employees by cutting their salaries or on their customers by raising the prices. These are unethical ways of bearing risk.

\subsubsection{Eco-Conscious Risk-Bearing}

Working with eco-friendly techniques and materials involve a lot of risk on the part of an entrepreneur, like - the possibility of low sales due to the product being different from the casual trend, risk of high cost emerged out of expensive eco-friendly materials, etc. Still, abiding by these risks is known as Eco-conscious Risk-bearing. Green Investments tend to yield long and safe returns. It is all about holding on to these kinds of risks.

\subsubsection{Autonomous Leadership}

Autonomy and Leadership contradict each other, as autonomy refers to self-governance and leadership is a team based concept. However, autonomous leadership is considered as a process, where the entrepreneur first guides himself and on being successful, he implements the same method of governance over his team members. 


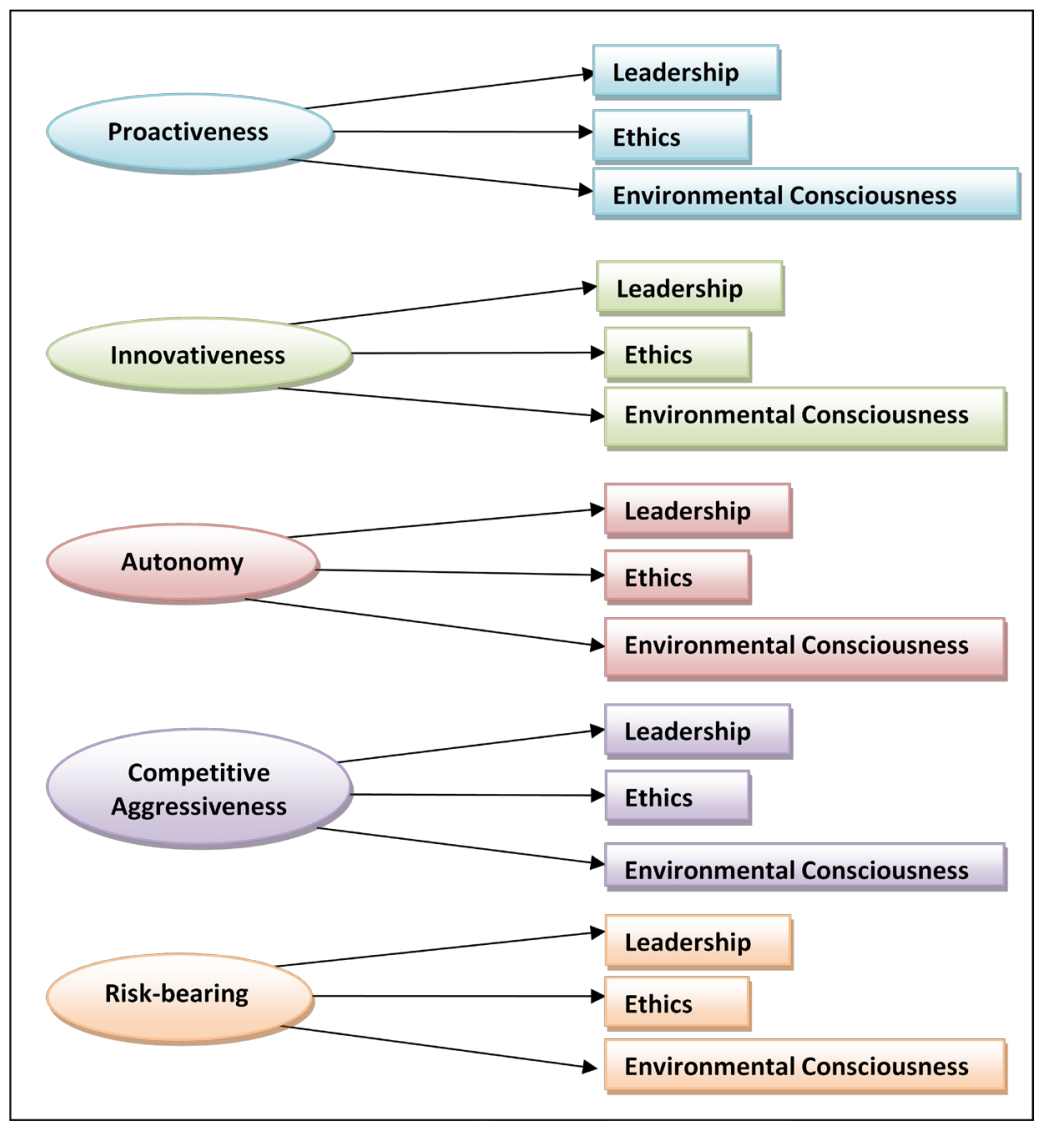

Figure 3. Linking of Entrepreneurial Dimensions with Sustainability Elements

\subsubsection{Ethical Autonomy}

Governance needs to be fair and principled. It should be delivered in a righteous intensity or else it may result in dictatorship. Ethics in a firm can be best followed, when the entrepreneur follows a code of conduct for himself. As by this, he sets an example for his member employees.

\subsubsection{Eco-Conscious Autonomy}

If an entrepreneur considers nature as his asset and takes special care of it, in a sense that he does not waste resources and utilizes them optimally, then he has the orientation of eco-conscious autonomy. It is required that he makes the members of his organization follow the same.

\subsubsection{Competitive Aggressive Leadership}

When the team is guided by an entrepreneur for scoring high on the boards of sales, production, consumer preference, etc, which means securing more business opportunities for their organization, with new strategies, ideas, and an organized approach, then it is said to have an orientation of Competitive Aggressive Leadership.

\subsubsection{Ethical Competitive Aggression}

In order to chase in the race, ethics are often set aside. Such a competition can never give in sustainable results. Spreading of business communications, exchanging ideas, forming business communities for mutual good, are some ways to enhance ethical competitive aggression.

\subsubsection{Eco-Conscious Competitive Aggression}

Developing of competition at the level of launching new ecological techniques and products and gaining consumer preference towards them, is the way to boost eco-conscious competitive aggression. However, this orientation requires a lot of extra effort and an out-of-the-box approach.

\section{Materials and Methods}

The section gives an overview of the methods and materials used while compiling this study, within the heads of Research Design, Sampling Design and Research Methods.

\subsection{Research Design}

The type of research design is Quantitative, as it features the statistical analysis done on the collected numerical data. It is a kind of Descriptive and Analytical Research and the data that framed this study is Primary and also Secondary in nature. The study was confined in a Single time-period and it commenced in the mid of January 2013. In a span of eight months, it was compiled to produce absolute results. The Geographical area of the research had been Agra Region, also known as the Braj Mandal. It is located in Uttar 
Pradesh, which is a renowned state of India.

\subsection{Sampling Design}

The Industry considered in this study has been the Handicrafts Industry. It is a prominent industry in Agra region that provides an entrepreneurial base to a diverse class of people. The target population had been the handicraft entrepreneurs of the areas as specified in table 1. All the prominent skills and craftsmanship spotted in the Agra region had been assembled in this study.

Table 1. Specifications of the Research Population

\begin{tabular}{|c|c|c|}
\hline No. & Category & Area covered \\
\hline 1.$)$ & $\begin{array}{c}\text { Rugs } \\
\text { (Jute Products \& Carpets) }\end{array}$ & Agra \\
\hline 2.$)$ & Marble Inlay Work & Agra \\
\hline 3.$)$ & Zari - Zardozi work & Agra \\
\hline 4.$)$ & Glass Handiwork & Firozabad \\
\hline 5.$)$ & Wooden Handicrafts & Vrindavan \\
\hline 6.$)$ & Textile Printing \& Dyeing & Mathura \\
\hline
\end{tabular}

The sample size comprised of 240 handicraft entrepreneurs, where, 40 entrepreneurs from each of the 6 specific handicraft units (table 1.) were taken. Convenient and Purposive Sampling were opted.

\subsection{Research Methods}

The data was collected using a Self-structured Questionnaire. An English to Hindi translated questionnaire / schedule also aided in reaching the respondents that were receptive in the native language. The Interval scale of measurement had been used, where an equidistant 7-point scale was given for the self-assessment of the efficiency of the entrepreneurs in associating the sustainability elements with the entrepreneurial dimensions within themselves. 45 statements were given to be marked on and the scale ranged from 1 to 7, symbolizing - "Strongly Disagree" to "Strongly Agree", respectively. The Response Rate had been $93.75 \%$ and the method adopted for data collection was door-to-door contact method. The reliability was tested through Cronbach Alpha's test, on the SPSS (Statistical Package for the Social Sciences) software. Microsoft Excel was used for implementing other statistical tools, which included - Averages, Percentages, Correlation, and ANOVA Single Factor Analysis. Graphs, diagrams and tables have been supportive in arranging the data in this research paper.

\section{Results}

On the basis of the responses gathered through the self-assessment of 240 handicraft entrepreneurs in Agra region, in context of possessing the Entrepreneurial dimensions and Sustainability elements within themselves, the results have been laid in two respects. First, the result portrays the state of association between the Entrepreneurial dimensions and Sustainability elements; and second, it reflects the status of the handicraft entrepreneurs on possessing Entrepreneurial dimensions with respect to each Sustainability element, individually.

\subsection{Association between Entrepreneurial Dimensions and Sustainability Elements}

The association of the Dimensions of Entrepreneurial Orientation with the Elements of Sustainability was tested by means of evaluating correlation between them. A null hypothesis was framed and analyzed for the same purpose.

$\boldsymbol{H}_{0}$ 1: There is no association between the dimensions of Entrepreneurial Orientation and elements of Sustainability in the Handicraft industries of Agra region

All the dimensions of Entrepreneurial Orientation and elements of Sustainability were compacted individually to give two major heads - Entrepreneurial Orientation and Sustainability, respectively. The correlation value was calculated as 0.889 for these two aspects, which is greater than the critical value in the Pearson Product-Moment Correlation (PPMC) co-efficient table, given as 0.182 at the 0.01 significance level, two-tailed for more than 200 observations [17]. Hence, we reject the first null hypothesis on the basis that a significantly and strongly positive relation between the two aspects has been proved. The correlation among the Entrepreneurial dimensions and Sustainability elements, pose being in linear association with each other, where if Entrepreneurial Dimensions are enhanced, then Sustainable Development is obvious to appreciate and attainment of Sustainability can be made possible.

\subsection{Status of Entrepreneurs on Possessing Integrated Entrepreneurial Dimensions and Sustainability Elements}

The handicraft entrepreneurs tend to possess Entrepreneurial dimensions and Sustainability elements, but how far are they incorporated and associated with one another has been a prime concern and hence, a hypothesis was tested in order to verify this conception.

$\boldsymbol{H}_{0}$ 2: Handicraft Entrepreneurs equally possess Entrepreneurial Dimensions with regards to Sustainability Elements

In order to analyze the stated hypothesis, three sub-hypotheses have been formed. Each element of Sustainability has been considered complete in itself, as they form an independent sustainability of their own. Each Entrepreneurial Dimension does not have an independent existence and assembling them altogether provides us with the Entrepreneurial Orientation Construct. Hence, the entrepreneurial dimensions have been worked out in context with each of the element of Sustainability - Leadership, Ethics, and Environment. 
$H_{0}$ 2a: Handicraft Entrepreneurs equally possess Entrepreneurial Dimensions with regards to Leadership

The evaluated reliability of the items has been high as evident from the alpha-values in table 2., where all are ranging above 0.8 . The mean values of all the parameters range above 5 and below 6.5, thereby illustrating the agreement of the entrepreneurs on possessing them. However, the risk-bearing leadership is found to be lowly acquired and competitive aggressive leadership is highly held, followed by proactive leadership.

On applying $\mathrm{F}$ - Test through ANOVA - single factor analysis, the $F_{\text {Calculated }}(13.071)>F_{\text {Critical }}$ (2.402), thus portraying that there is significant mean difference in possession of Entrepreneurial dimensions with regards to Leadership. On this basis, we reject the first sub-hypothesis, confirming that Handicraft Entrepreneurs do not equally possess Entrepreneurial dimensions with regards to leadership.

Table 2. Presence of Entrepreneurial Dimensions with regards to Leadership

\begin{tabular}{|c|c|c|c|}
\hline Parameter & $\begin{array}{c}\text { Cronbach } \\
\text { Alpha }\end{array}$ & Mean & Variance \\
\hline Proactive Leadership & 0.829 & 6.267 & 0.176 \\
\hline Innovative Leadership & 0.827 & 6.1 & 0.724 \\
\hline Risk-bearing Leadership & 0.819 & 5.433 & 1.515 \\
\hline Autonomous Leadership & 0.894 & 5.7 & 0.688 \\
\hline $\begin{array}{c}\text { Competitive Aggressive } \\
\text { Leadership }\end{array}$ & 0.834 & 6.3 & 0.191 \\
\hline
\end{tabular}

$\mathbf{H}_{\mathbf{0}}$ 2b: Handicraft Entrepreneurs equally possess Entrepreneurial Dimensions with regards to Ethics

The statements that linked Entrepreneurial dimensions with Ethical attributes were analyzed. The reliability of the items considered has been found high. It is manifested by the Cronbach's alpha-values in table 3., where all are ranging above 0.8 , which is far satisfactory than the required value of 0.7. The mean values depict the agreement of the entrepreneurs on possessing all the parameters, however, ethical proactiveness is less found and ethical autonomy is highly acquired with a mean value of 6.7 . Ethical Risk-bearing is followed thereon.

Table 3. Presence of Entrepreneurial Dimensions with regards to Ethics

\begin{tabular}{|c|c|c|c|}
\hline Parameter & $\begin{array}{c}\text { Cronbach } \\
\text { Alpha }\end{array}$ & Mean & Variance \\
\hline Ethical Proactiveness & 0.830 & 5.033 & 1.095 \\
\hline Ethical Innovativeness & 0.818 & 5.7 & 0.553 \\
\hline Ethical Risk-bearing & 0.840 & 6.4 & 0.199 \\
\hline Ethical Autonomy & 0.847 & 6.7 & 0.078 \\
\hline $\begin{array}{c}\text { Ethical Competitive } \\
\text { Aggression }\end{array}$ & 0.814 & 5.733 & 0.470 \\
\hline
\end{tabular}

The $F_{\text {Calculated }}(53.501)>F_{\text {Critical }}(2.402)$ and it shows a significant mean difference in possession of Entrepreneurial dimensions with regards to Ethics. On this basis, we reject second sub-hypothesis, substantiating that Handicraft Entrepreneurs do not equally possess Entrepreneurial dimensions with regards to ethics.

$\boldsymbol{H}_{0} 2 c$ : Handicraft Entrepreneurs equally possess Entrepreneurial Dimensions with regards to Environmental Consciousness

The reliability of the parameters taken has been high as apparent from the alpha-values in table 4., where all are above 0.8 . The mean values of all the parameters range above 4.5 and they considerably vary from each other. Though, the overall mean is observed to be 5.38. This depicts the average conformity of the entrepreneurs on possessing entrepreneurial dimensions with respect to environmental consciousness. It has been observed that eco-conscious innovativeness is least found and eco-conscious autonomy is most found.

Table 4. Presence of Entrepreneurial Dimensions with regards to Environmental Consciousness

\begin{tabular}{|c|c|c|c|}
\hline Parameter & $\begin{array}{c}\text { Cronbach } \\
\text { Alpha }\end{array}$ & Mean & Variance \\
\hline Eco-conscious Proactiveness & 0.810 & 5.2 & 0.795 \\
\hline Eco-conscious Innovativeness & 0.824 & 4.767 & 1.041 \\
\hline Eco-conscious Risk-bearing & 0.839 & 5.133 & 0.999 \\
\hline Eco-conscious Autonomy & 0.836 & 6.567 & 0.182 \\
\hline Eco-conscious Competitive & 0.812 & 5.233 & 0.860 \\
\hline
\end{tabular}

The $F_{\text {Calculated }}(36.740)>F_{\text {Critical }}(2.402)$, thus, verifying that there is significant mean difference in acquirement of Entrepreneurial dimensions with regards to Environmental Consciousness. On this piece of evidence, we reject the third sub-hypothesis, authenticating that Handicraft Entrepreneurs do not equally possess Entrepreneurial dimensions with regards to Environmental Consciousness.

The second hypothesis was framed with the integration of the three sub-hypotheses, all of which have been notably rejected. Consequently, it leads to the rejection of the second null hypothesis. This approves that the Handicraft Entrepreneurs do not equally possess Entrepreneurial Dimensions as regards to the Elements of Sustainability.

\section{Instilling Sustainability Elements into Entrepreneurial Base: A Framework}

With the best of their potential, the entrepreneurs are running their enterprises. However, for the consistent and healthy development of the business enterprises, entering of sustainability orientation into the equation is actually meaningful [1]. Thus, for the effective entrepreneurial execution, a framework (figure 4.) has been fabricated. It 
classifies the entrepreneurs into two groups. Firstly, the Prospective Entrepreneurs, which are those pursuing business studies in present so to become entrepreneurs in the approaching time. Secondly, the Existing Entrepreneurs are the ones that in the active state are running their business enterprises and are contributing in the economy. They denote the future and the present generations, respectively. The framework considers respective authorities that can cause a change in these two groups. The authority that can best influence the Prospective Entrepreneurs is the Academic body and it is the Government that is looked upon by the Existing Entrepreneurs for their assistance. To evolve a complete transformation, there are three phases that should be chased. Succeeding in these three stages shall result in sustenance of the change. Thus, the three steps are -

- Initiating the change by creating a better understanding of the process

- Adopting the change by implementing upon the principles

- Sustaining the change by developing a favorable attitude towards it

\subsection{First Step}

How far can a man go without the knowledge of the routes and destination? Thus, the first step of the framework is to create awareness. It is required that the entrepreneurs gain knowledge about the concept, features, benefits and opportunities of Sustainable Development. "Sustainability Thinking" offers a guiding template for both research and management towards the goal of sustainability [16]. For prospective entrepreneurs, it can be facilitated by adding subjects and term papers in the curriculum on Sustainable Development and Entrepreneurial Orientation, like Leadership Orientation, Practical Aspects on Business Sustainability, Green Businesses, Ethics ad Business, etc. Integrating Sustainability into both the curriculum and co-curriculum can be complementary [2]. For the Existing Entrepreneurs, the tenure of getting effective academic teachings is almost over, so it becomes the duty of the government to arrange for certain workshops of short duration upon clarifying the concepts of Sustainable Development, working upon the principles of Sustainability, balancing the Entrepreneurial dimensions with the elements of Sustainability, etc. In this way, the two generations can be acquainted with the concept of Sustainability.

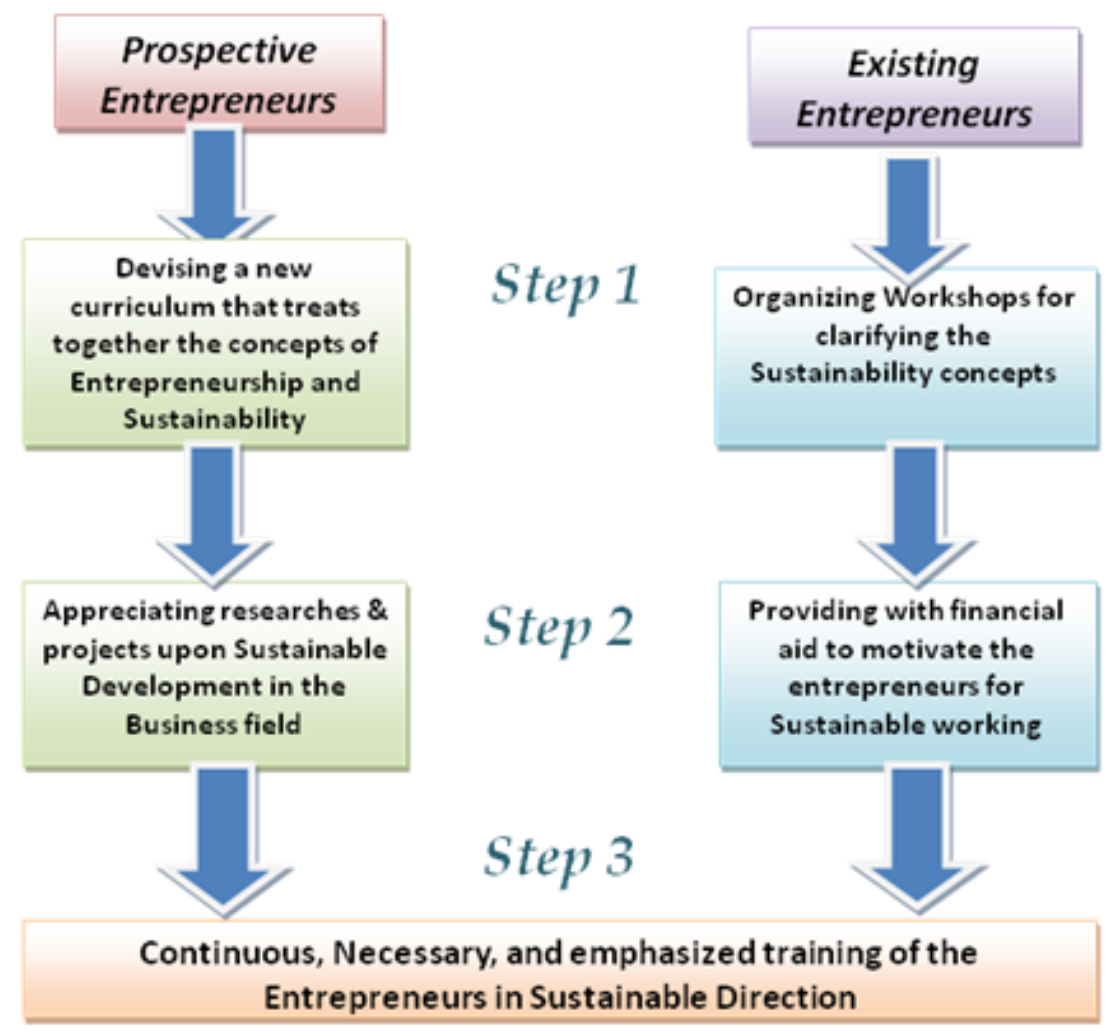

Figure 4. The Framework for effective Entrepreneurial execution by Business Enterprises for Sustainable Development 


\subsection{Second Step}

After generating the awareness amongst the entrepreneurs, the next big step is to practically implement all that have been learned on the first step. At the academic level, the prospective entrepreneurs are needed to do researches on the concerning issues of Sustainable Development and Entrepreneurial Orientation. Furthermore, case-studies, vocational trainings, internships, etc. and engaging in projects on Sustainability issues and practically relating them in Business field, shall help in achieving and sustaining development in business enterprises. On the other hand, the existing entrepreneurs require financial aid from the government bodies. It has been analyzed that what averts entrepreneurs from making green investments is the high cost of the eco-friendly products and materials, low sales due to less preference of the consumers which is due to high pricing of the products. Thus, government needs to interfere on this and provide incentives and subsidies to those entrepreneurs that support green production and investments, respectively.

\subsection{Third Step}

As the awareness is created and execution of the practical aspects begins, the last but the most important step is to continue this process of implementation. It is very important to build a likely attitude towards the same, which is only possible by the continuous hammering done in that very direction. It needs effortful working for some time, so that later it is habituated. A common way for both - prospective and existing entrepreneurs is to make an arrangement, where continuous, emphasized and compulsory training is undertaken by the entrepreneurs in the direction of Sustainable working. Effectiveness in their entrepreneurial orientation can also be monitored in this step. The task of necessitating is very important, as things not made mandatory are often ignored. The respective authorities need to inspect, manage and also frequently reward their variables for their achievements.

\section{Conclusion}

The paper has explored the status of the Entrepreneurs regarding the acquirement of Entrepreneurial Orientation dimensions and Sustainability elements, which were though found but not in equal proportions. The two concepts are positively correlated with each other as per the analysis. On studying the importance and barricades regarding the implementation of the two concepts, a framework was devised in this research paper. It will support in the effective entrepreneurial execution of the business enterprises for Sustainable Development. If it is followed stepwise, it will affirm the foundation of the long term progress. With the permeation of the elements of Sustainability, the framework ensures enhancement of the productivity of the entrepreneurs and also healthy and escalated development of the business world as also of the planet.

Ever-increasing production and consumption - the base of the modern economy has become unsustainable. Economics does not stand on its own feet, but instead it is derived from a view of the meaning and purpose of life [11]. The entrepreneurs who do choose to make sustainability a key pillar of their corporate strategy can be more competitive and can more closely align sustainability investments with returns [10]. The Education system and the Government bodies play an important role in assisting the Entrepreneurs of a country to establish Sustainable Business enterprises. The Consumers act as the motivational force in the foundation of such enterprises. Sustainable Organizational set-ups are desirable and they will be the only life-line left in the near future. Getting hold of them on this day will assure a safe natural world that will further substantiate healthy living of the community and also fair returns in the economy.

\section{REFERENCES}

[1] Andreas Kuckertz, Marcus Wagner. The Influence of Sustainability Orientation on Entrepreneurial Intentions Investigating the Role of Business Experience, Journal of Business Venturing, Vol. 25, No. 5, 524-539, 2010.

[2] Cathy A. Rusinko. Integrating Sustainability in Management and Business Education: A Matrix Approach, Academy of Management Learning \& Education, Vol. 9, No. 3, 507 - 519, 2010 .

[3] Danny Miller, Peter H. Friesen. Innovation in Conservative and Entrepreneurial Firms: Two Models of Strategic Momentum, Strategic Management Journal, Vol. 3, 1 - 25, 1982.

[4] Danny Miller. The Correlates of Entrepreneurship in Three Types of Firms, Management Science, Vol. 29, No. 7, $770-$ $791,1983$.

[5] David Gibbs. Sustainability Entrepreneurs, Ecopreneurs and the Development of a Sustainable Economy, Greener Management International, Vol. 55, 63 - 78, 2009.

[6] F. Harvey. Start Me Up, Green Futures, Vol. 65, 18 - 25, 2007.

[7] G. Thomas Lumpkin, Gregory G. Dess. Clarifying the Entrepreneurial Orientation Construct and Linking it to Performance, The Academy of Management Review, Vol. 21, No. 1, 135-172, 1996.

[8] Jeffrey G. Covin, Dennis P. Slevin. Strategic Management of Small Firms in Hostile and Benign Environments, Strategic Management Journal, Vol. 10, 75 - 87, 1989.

[9] Johan Wiklund. The Sustainability of the Entrepreneurial Orientation - Performance Relationship, Entrepreneurship Theory and Practice, Vol. 24, No. 1, 37 - 48, 1999.

[10] John Peloza, Moritz Loock, James Cerruti, Michael Muyot. Sustainability: How Stakeholder Perceptions differ from Corporate Reality, California Management Review, Vol. 55, No. 1, $74-95,2012$. 
[11] Jyoti Gogia. The Present Economic System: Divergence from Aspiration (Need to Realize a Conscious Economic System for a Better World Order), Advances in Economics and Business, Vol. 1, No. 2, 139 - 144, 2013.

[12] Ki-Hoon Lee, Robert Ball. Achieving Sustainable Corporate Competitiveness, Greener Management International, Vol. 44, $89-104,2003$.

[13] Mark Diesendorf. 'Sustainability and Sustainable Development', in D. Dunphy, J. Benveniste, A. Griffiths, and P. Sutton (eds), Sustainability: The corporate challenge of the 21st century, Sydney: Allen \& Unwin, Chapter - 2, 19-37, 2000.

[14] Obeua Persons. Incorporating Corporate Social Responsibility and Sustainability into a Business Course: A Shared Experience, Journal of Education for Business, Vol.
87, No. 2, $63-72,2012$.

[15] Pradip N. Khandwalla. Some Top Management Styles, their Context and Performance, Organization and Administrative Sciences, Vol. 7, No. 4, $21-51,1977$.

[16] Terry Porter, Robin Derry. Sustainability and Business in a Complex World, Business and Society Review, Vol. 117, No. $1,33-53,2012$.

[17] The Pearson Product-Moment Correlation (PPMC) Co-efficient table. Appendix 1, Table A9, http://www.uwe.ac.uk/hlss/llas/statistics-in-linguistics/Appe nix 1.pdf

[18] WCED (World Commission on Environment and Development), Our Common Future, Oxford University Press, Oxford, 1987. 